\title{
Recommendations for methane prognostics and adjustment of short-term prevention measures based on methane hazard levels in coal mine longwalls
}

\author{
A.P. Niewiadomski, H. Badura, and G. Pach \\ Faculty of Mining, Safety Engineering and Industrial Automation, Department of Mining, Silesian \\ University of Technology, Poland
}

\begin{abstract}
The article describes the recommended procedure for conducting methane forecasts and selection of the methane prevention measures that adequately reflect the level of risk of methane combustion and explosion. The appropriate selection of measures to prevent methane exposure can be effective at mitigating the exposure risk of the miners and other mine employees. Implementation of these measures can have the additional benefit of increasing mine output and efficiency. For example, prediction of methane concentrations can reduce the instances of unplanned equipment downtime to maintain mine safety and integrity. The presented procedure is the culmination of extensive research on three predictive models of short-term average methane concentrations. Identifying the advantages and disadvantages of the models became possible by verifying the models against a nearly 500 -day dataset obtained from 7 longwalls with identified significant methane content. Furthermore, selected studies were presented based on one of the datasets obtained from the U-ventilated longwall.
\end{abstract}

\section{Introduction}

High methane concentrations are currently one of the most significant natural hazards in the hard coal mining industry [1-4]. The occurrence of undesirable concentrations may result in delays in the production process and measurable economic losses, as well as directly affect the safety of mining crews working in the longwall area [5]. Reports prepared by the Higher Mining Authority, which is the supervising mining body in Poland, indicate that the industry is likely to see an increase in the measured methane values in longwalls despite continuous development in the area of methane drainage technology.

In order to lower the methane risk level, mine ventilation departments must carry out extensive preventive measures, the scope of which must be appropriate to the risk level. According to the Polish legislation rigors, calculations to determine the absolute methanebearing capacity in methane threatened longwall areas should be prepared at least monthly, and in longwall seams examined as level II-IV methane hazard category, this should be carried out at least once a day. Moreover, absolute methane-bearing capacity forecasts for the total longwall lifetime should be prepared during the pre-launch stage. 
These regulations apply to longwalls located directly inside or in the vicinity (up to $120 \mathrm{~m}$ over and up to $60 \mathrm{~m}$ beneath the longwall) of level II-IV methane hazard category seams [6]. Methane level predictions at the pre-exploitation stage are the basis for criteria methane-bearing capacity calculations. The calculations are necessary to determine methane prevention measures which ensure that methane concentrations will not be exceeded [6,7]. The actual methane threat level is affected by many factors, often characterized by high dynamics [8-15]. As a consequence, more accurate identification of the methane threat is possible only after the commencement of exploitation and requires the collection of relevant data, which is the subject of many publications in Poland and abroad $[8,16-21]$. Therefore, it is essential to choose the appropriate prediction model to minimize error and ensure the continued safe operation of the mine [22].

The model described by Instruction No. 14 of the Polish Central Mining Institute, utilized for the absolute methane-bearing capacity forecasts, is widely used [23]. According to the model, the forecast values are determined by the calculated amount of methane emitted from various sources (1):

$$
\dot{V}_{M C}=1,488 p^{-0.32}\left(\dot{V}_{1}(p)+\dot{V}_{2}(p)+\sum_{i=1}^{i=n} \dot{V}_{3,5}(p)+\sum_{i=1}^{i=n} \dot{V}_{4,6}(p)\right)
$$

where:

$\dot{V}_{M C}$ - absolute methane-bearing capacity in the longwall area $\left[\mathrm{m}^{3} / \mathrm{min}\right]$,

$p$ - daily exploitation volume in monthly ranges $[\mathrm{m} / \mathrm{d}]$,

$\dot{V}_{1}(p)$ - methane released from extracted coal $\left[\mathrm{m}^{3} / \mathrm{min}\right]$,

$\dot{V}_{2}(p)$ - methane released from longwall face $\left[\mathrm{m}^{3} / \mathrm{min}\right]$,

$\dot{V}_{3,5}(p)$ - methane released from coal seam or gas-bearing strata layer located above longwall $\left[\mathrm{m}^{3} / \mathrm{min}\right]$,

$\dot{V}_{4,6}(p)$ - methane released from coal seam or gas-bearing strata layer located beneath longwall $\left[\mathrm{m}^{3} / \mathrm{min}\right]$.

The key factor influencing the accuracy of forecasts prepared with this model is the proper recognition of the methane content distribution in the exploited seam and other gasbearing layers and seams in the longwall desorption zone. The methane content distribution in an operated seam is determined by borehole samples taken at regular intervals and its measurement is a relatively simple process. However, methane content in seams above or below the longwall is usually assumed, since these deposits are often not mined and are not subject to methane content analysis.

To minimize the aforementioned potential forecast errors that can arise during the longwall pre-launch stage, it is possible to use short-term prediction models [16] as the supporting tool. These group models provide for methane hazard level prediction based on current measurements obtained from the automatic methanometric system and exploitation volume data. They can be used to forecast daily methane concentrations in a one-day or maximum fourteen-day time horizon.

Short-term methane prediction models could be utilized for average and maximum daily methane concentration forecasting at the longwall ventilation outlets, as well as foridentifying specific concentration values over time. The published literature [16,22] indicates that the best reflection of the actual conditions is obtained by the models that take into account daily exploitation volumes (2). 


$$
M C_{A}=a_{0}+a_{1} M C_{A 1}+a_{2} E V_{d}+a_{3} E V_{d 1}+\varepsilon
$$

where:

$M C_{A}$ - forecasted volumetric daily average methane concentration [\%],

$M C_{A 1}$ - volumetric daily average methane concentration on the previous day [\%],

$E V_{d}$ - planned daily exploitation volume on the day for which forecast is prepared $[\mathrm{t} / \mathrm{d}]$,

$E V_{d 1}$ - daily exploitation volume on the previous day $[\mathrm{t} / \mathrm{d}]$,

$a_{0} a_{1} a_{2} a_{3}-$ approximated model parameters,

$\varepsilon$-residual coefficient (the difference between the measured and forecasted values).

However, this model requires collecting the appropriate data in order to approximate model parameters. There are currentlyone-day average methane prediction models, which can be utilized after one day of longwall operation [16]. These models are in the form of linear functions, in which the average methane concentration for the previous day is an independent variable and can be prepared for each day of the week (3). The application of such a solution is possible due to the weekly fluctuations of average methane concentrations $[16,24]$. Parameters of the prediction model (3) for each day of the week are presented in Table 1. They were estimated empirically, based on a vast measurements database from various longwalls.

$$
M C_{A}=a M C_{A 1}+b
$$

where:

MC- volumetric daily average methane concentration on the previous day [\%],

$a, b$-empirical function parameter values for each day of the week.

Table 1. Forecast models parameters [16].

\begin{tabular}{cccc}
\hline \multicolumn{2}{c}{ Day of the week } & \multirow{2}{*}{ a parameter value } & \multirow{2}{*}{ b parameter value } \\
\hline Examined $(\mathrm{t})$ & Preceding $(\mathrm{t}-1)$ & & 0,7373 \\
\hline Monday & Saturday & 0,9623 & 0,1723 \\
Tuesday & Monday & 0,9014 & 0,1256 \\
Wednesday & Tuesday & 0,9405 & 0,1027 \\
Thursday & Wednesday & 0,9459 & 0,0468 \\
Friday & Thursday & 0,7213 & 0,0458 \\
Saturday & Friday & 0,7667 & 0,0869 \\
Sunday & Saturday & & 0,0534 \\
\hline
\end{tabular}

\section{Methods of research}

The goal of this article was to determine and compare the accuracy of the selected methane concentration prediction models in terms of the effective selection of methane-prevention measures. Additionally, criteria for their applicability have been established.

In order to conduct the research, measurement data sets were obtained, including measurements of methane concentrations and air velocity at longwall ventilation area outlets (continuous measurement reports), dimensions of the longwalls and the surrounding excavations, as well as dispatcher reports. The collected database serves as a test set for the forecast preparation using three models during the observation period, which were then subject to statistical analysis [22].

One of the datasets selected for analysis included the U-1 longwall ventilation area at one of the Upper Silesian Coal Basin mines. The selected U-1 longwall had the following geometrical parameters: 
- length - ca. $210 \mathrm{~m}$,

- panel length - ca. $1115 \mathrm{~m}$,

- face height $-2.3 \mathrm{~m}$,

- longitudinal slope ca. $0^{\circ}-5^{\circ}$.

The U-1 longwall was operated in a longitudinal system with caving. Ventilation was implemented in the U system (Fig. 1).

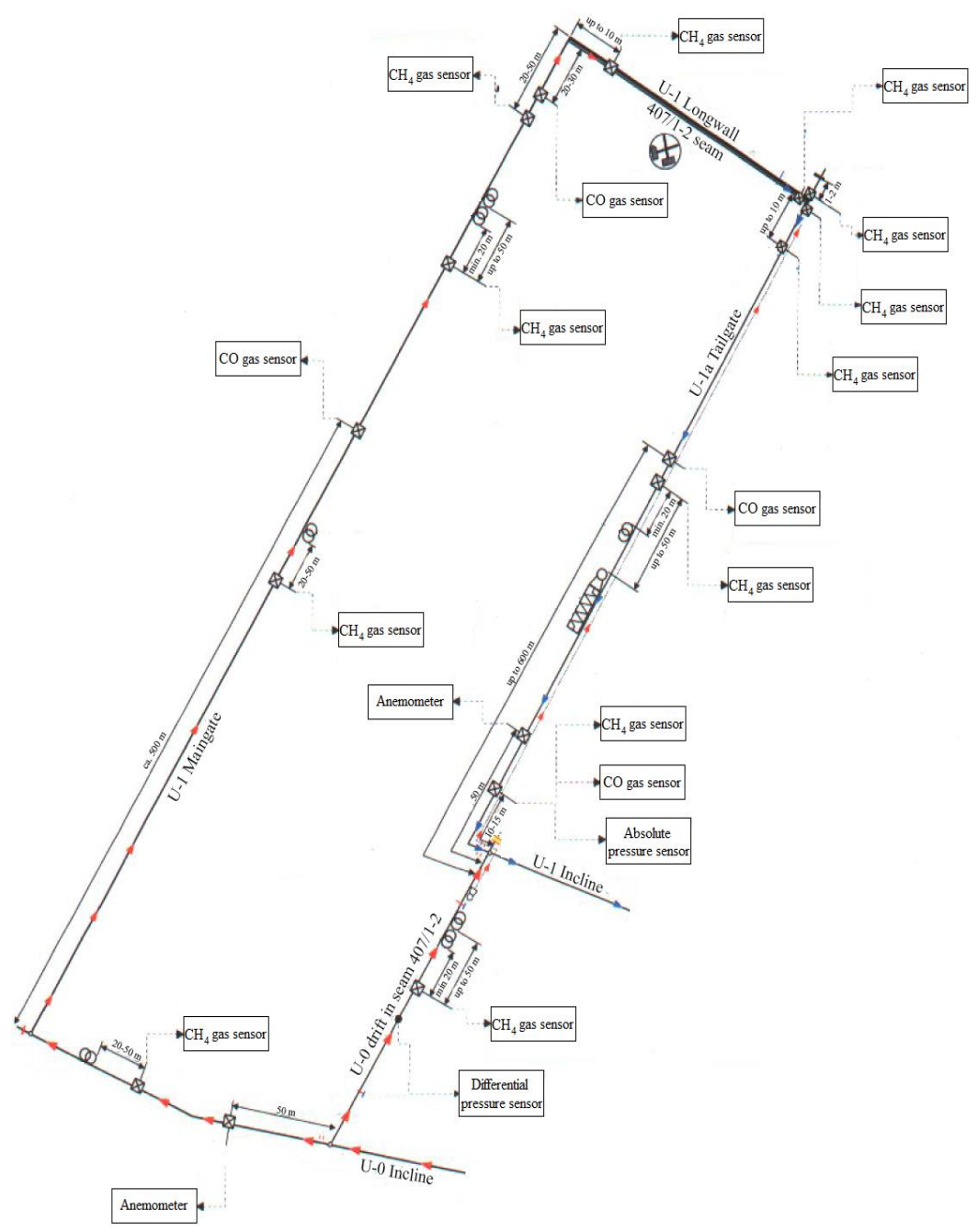

Fig. 1. U-1 longwall ventilation area (U-1 longwall project 2018.

Based on the obtained measurements - themean, minimum, and maximum methane concentration profiles were determined. All the records came from automatic methane analyzers located at the U-1 longwall ventilation outlet and covered 101 subsequent days of observation (Fig. 2). 


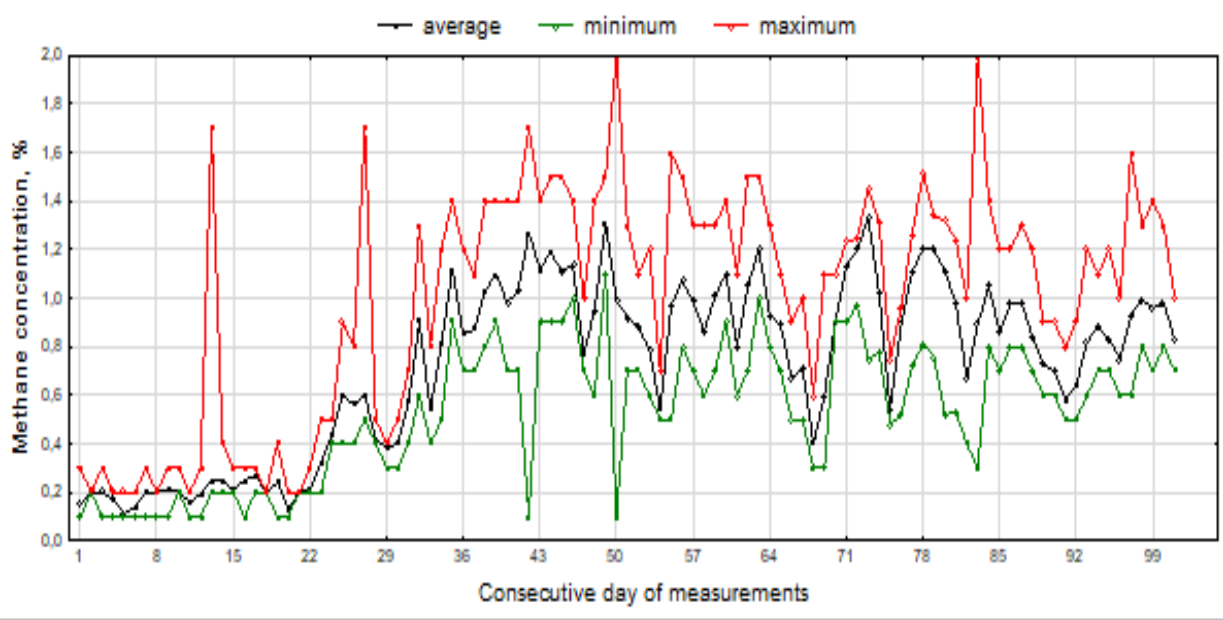

Fig. 2. Mean, minimum and maximum daily methane concentration at the outlet of U-1 ventilation area.

The U-1 longwall methane profile begins with its launch, which is perfectly illustrated by the time series of mean, maximum, and minimum daily concentrations of methane.Based on the data analysis, 21 days were identified in which no exploitation was conducted. The distribution of the maximum daily methane concentrations presupposes the occurrence of gas-dynamic phenomenacausing short-term but intense outflows of high methane concentrations in the vicinity of the longwall.

Figure 3 illustrates one-day-ahead forecasts for the three studied forecasting models. The models illustrated in Figure 3 are described below:

- an absolute methane-bearing capacity dynamic prediction model (converted to daily average methane concentrations) developed at the Polish Central Mining Institute, hereinafter referred to as model_1 - eq. (1) [23],

- an autoregressive one-dayaverage methane concentration prediction models for each day of the week developed at the Silesian University of Technology, hereinafter referred to as model_2-eq. (3) [16],

-acause-effect one-dayaverage methane concentration prediction model developed at the Silesian University of Technology, hereinafter referred to as model_3 - eq. (2) [16].

The length of the observation period was reduced in order to prepare an appropriate input dataset for the approximation of model_3 parameters. Moreover, the conversion of model_1 absolute methane-bearing capacity forecasts to average daily methane concentrations was performed. For the conversion, data obtained from anemometers, longwall, and tailgate dimensional parameters, and daily longwall face advancement were used.

The results indicate that model_2 and model_3 graphs most closely correlate with the daily methane concentration fluctuations (Fig. 3). It should be noted that model_1 forecast values are lower than the actual values recorded on given days $96 \%$ of the time. Such undervalued predictions may have a significant impact on the safety level when using this model. 


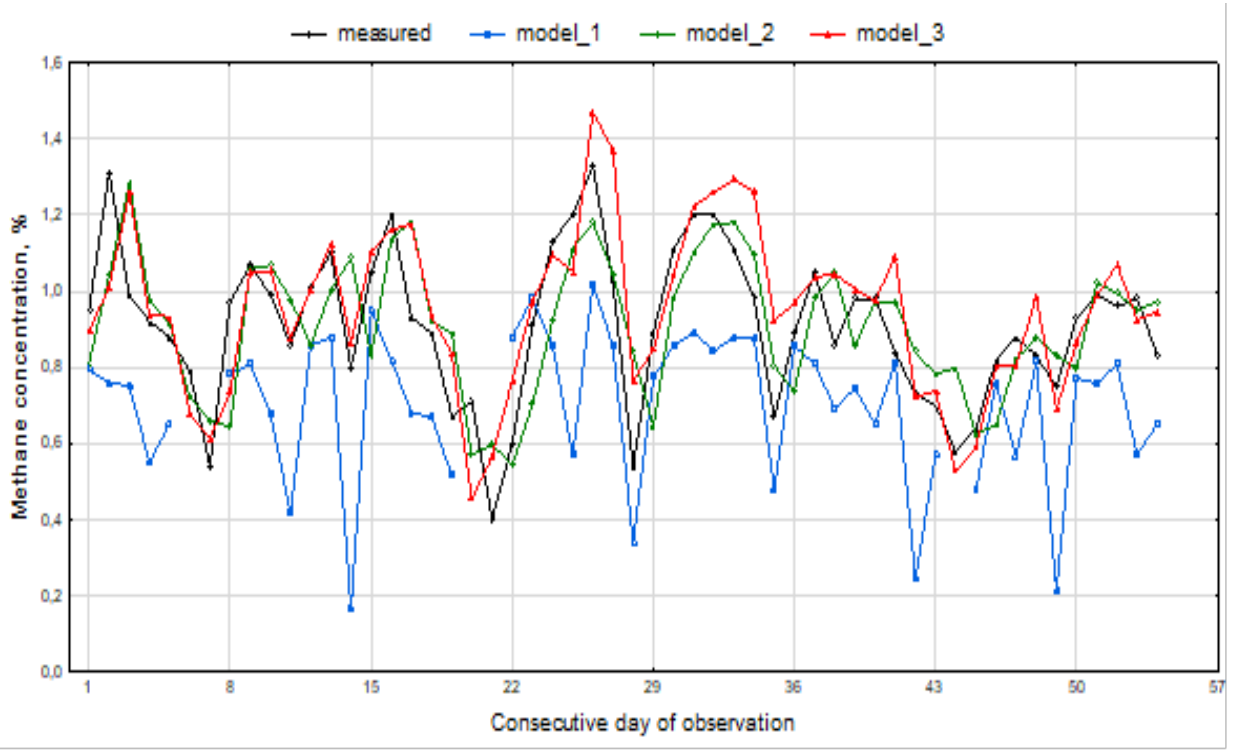

Fig. 3. Comparison of forecast and measured average methane concentration values at the outlet of U1 ventilation area.

Selected statistical parameters of absolute and relative forecast errors are listed in Table 2. It should be noted that the model_1 errors are more than double compared to the values that characterize model_2 and model_3 results. Furthermore, the values of the mean and median error parameters indicate that model_3 predictions are the most accurate.

The median of the absolute and relative model_3 errors is significantly lower than the mean value. The maximum, upper quartile and ninth decile values of model_2 and model_3 errors are similar. Such a distribution suggests that model_3 would be preferred over model_2 when predicting methane concentrations where relatively low average methane concentrations are anticipated. This is also confirmed by the fact that the difference between the maximum absolute error of model_2 and model_3 forecasts is only $0.02 \%$ $\mathrm{CH}_{4}$, while the difference between the relative errors of these models is $13 \% \mathrm{CH}_{4}$.

Table 2. Statistical parameters of absolute and relative U-1 forecasts errors.

\begin{tabular}{|c|c|c|c|}
\hline & model_1 & model_2 & model_3 \\
\hline Parameter & \multicolumn{3}{|c|}{ absolute error. ${ }^{\circ} \mathrm{CH}_{4}$} \\
\hline mean & 0.25 & 0.13 & 0.11 \\
\hline median & 0.23 & 0.12 & 0.06 \\
\hline third quartile & 0.31 & 0.19 & 0.17 \\
\hline ninth decile & 0.45 & 0.25 & 0.25 \\
\hline maximum & 0.64 & 0.33 & 0.35 \\
\hline Parameter & \multicolumn{3}{|c|}{ relative error. \% } \\
\hline mean & 27 & 15 & 13 \\
\hline median & 23 & 13 & 8 \\
\hline third quartile & 32 & 21 & 21 \\
\hline ninth decile & 48 & 31 & 30 \\
\hline maximum & 80 & 55 & 42 \\
\hline
\end{tabular}

The analysis of forecast errors distribution in particular value ranges (Fig. 4 and 5) indicates that the absolute errors in the range up to $0.10 \% \mathrm{CH}_{4}$ (automatic methane analyzers measurement error) achieve $14 \%$ of the forecasts made with the model_1 procedure, $44 \%$ of the model_2 forecasts and $61 \%$ of the model_3 forecasts. In the range up 
to $0.20 \% \mathrm{CH}_{4}$ forecast absolute errors, the values achieved are $43 \%$ by model_ $1,78 \%$ by model_2, and $81 \%$ by model_3, respectively. The in-depth analysis of the model_2 and model_3 errors showed that in more than half of the days in which error values exceed $0.20 \% \overline{\mathrm{CH}} \mathrm{H}_{4}$ they occurred on the same days for both models. This indicates the possibility of atypical events during those days.

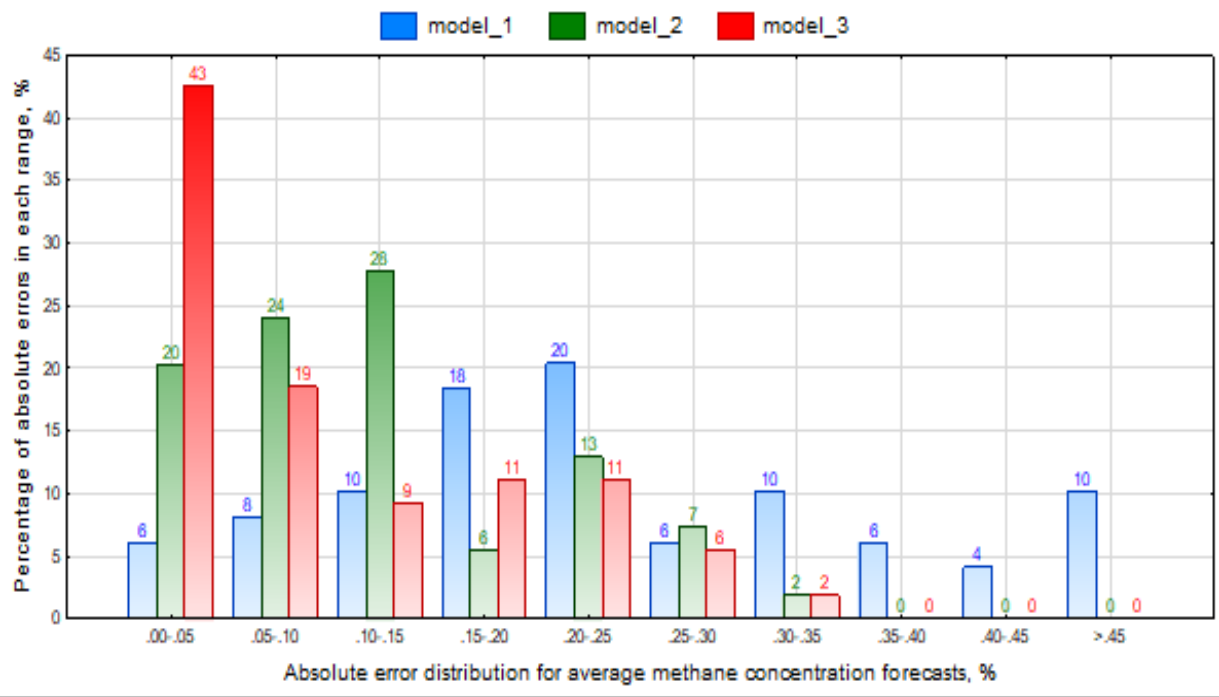

Fig. 4. Percentage of absolute errors of average methane concentration forecasts.

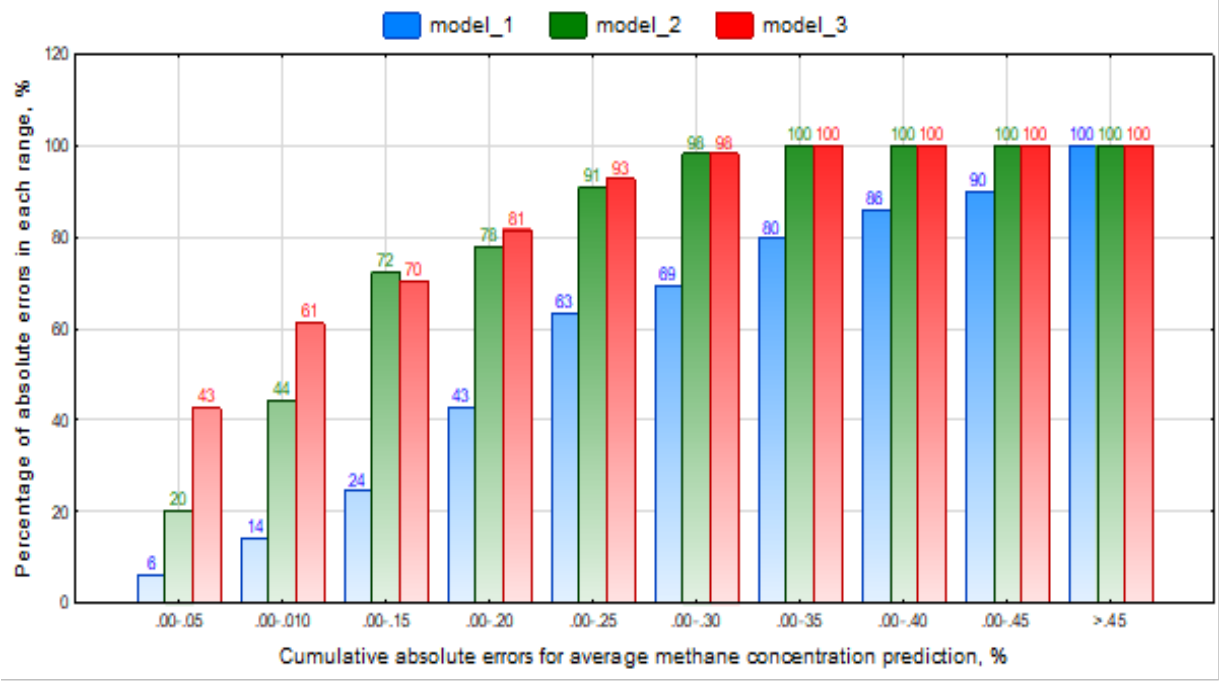

Fig.5. Percentage of absolute errors of average methane concentration forecasts in increasing ranges of error values.

Two days in the observed range were particularly unusual. The absolute error in the 2nd and the 27 th day of the dataset exceeded $0.30 \% \mathrm{CH}_{4}$. On the $2^{\text {nd }}$ day, the forecasted value was lower than the measured value. This was the result of ventilation disturbances, but it did not affect the safety level.

Additionally, the analysis of the 27 th day revealed the $1 \cdot 10^{4} \mathrm{~J}$ tremor occurrence on the preceding day, with the epicenter located directly in front of the longwall face. This 
phenomenon was the probable cause of the recorded $30 \%$ increase in the average measured methane concentration on the day for which the forecast was made, and thus the origin of the high error.

The conducted forecasts error analyses in the selected observation period allowed the following observations to be drawn:

1. Model_1 is characterized by high errors, resulting in the poor quality of forecasts. Moreover, the limitations of the model do not allow to make a methane prediction for days when exploitation does not occur.

2. Forecasts made by model_2 and model_3 revealed a satisfactory prediction of methane concentrations. The results prove that both of the tested models can be used effectively for adjustment of the scope of methane prevention measures.

3. Model_3 prediction errors are lower than errors of model_2. This trend is increasing particularly towards the end of the observation period. It indicates that increasing the observation period increases the level of model adaptation to the longwall-specific conditions. Moreover, the advantage of model_3 is that it can also be used to determine the maximum daily longwall face advancement at which the values of the average methane concentrations should not exceed the established limit value.

\section{Results and discussions}

This article presents a dataset of methane measurements obtained from the U-1 longwall and was extended and included in the database of total 7 longwalls with identified significant methane content. The length of the observation datasets in each particular longwalls was respectively (all the longwall names due to some sensitive data included in the database were coded):

$$
\begin{aligned}
& \text { - } \mathrm{U}-1-54 \text { days, } \\
& \text { - }-2-54 \text { days, } \\
& \text { - Y-1 - } 90 \text { days, } \\
& \text { - Y-2 - } 79 \text { days, } \\
& \text { - Y-3 - } 90 \text { days, } \\
& \text { - Y-4 - 61 days, } \\
& \text { - Y-5 - } 60 \text { days. }
\end{aligned}
$$

\begin{tabular}{|c|c|c|c|c|}
\hline & & model_1 & model_2 & model_3 \\
\hline & Parameter & \multicolumn{3}{|c|}{ absolute error, $\% \mathrm{CH}_{4}$} \\
\hline \multirow{5}{*}{ 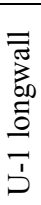 } & mean & 0.25 & 0.13 & 0.11 \\
\hline & median & 0.23 & 0.12 & 0.06 \\
\hline & third quartile & 0.31 & 0.19 & 0.17 \\
\hline & ninth decile & 0.45 & 0.25 & 0.25 \\
\hline & maximum & 0.64 & 0.33 & 0.35 \\
\hline \multirow{5}{*}{ 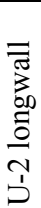 } & mean & 0.71 & 0.09 & 0.04 \\
\hline & median & 0.70 & 0.07 & 0.04 \\
\hline & third quartile & 1.05 & 0.13 & 0.05 \\
\hline & ninth decile & 1.29 & 0.22 & 0.09 \\
\hline & maximum & 1.46 & 0.32 & 0.15 \\
\hline
\end{tabular}

The lettering indicates the ventilation system applied in the particular longwalls. The tests of the remaining sets of measures in the database were carried out in the same manner as for longwall U-1. These tests, to a certain extent, repeated the results achieved with the presented example (Tab. 3).

Table 3. Statistical parameters of forecasts absolute errors. 


\begin{tabular}{|c|c|c|c|c|}
\hline \multirow{5}{*}{ 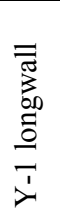 } & mean & 0.33 & 0.10 & 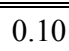 \\
\hline & median & 0.28 & 0.07 & 0.08 \\
\hline & third quartile & 0.48 & 0.13 & 0.14 \\
\hline & ninth decile & 0.64 & 0.27 & 0.21 \\
\hline & maximum & 1.02 & 0.51 & 0.33 \\
\hline \multirow{5}{*}{ 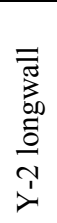 } & mean & 0.46 & 0.15 & 0.20 \\
\hline & median & 0.45 & 0.12 & 0.18 \\
\hline & third quartile & 0.66 & 0.22 & 0.28 \\
\hline & ninth decile & 0.79 & 0.31 & 0.44 \\
\hline & maximum & 1.07 & 0.53 & 0.53 \\
\hline \multirow{5}{*}{ 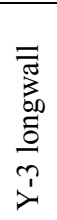 } & mean & 0.42 & 0.07 & 0.06 \\
\hline & median & 0.38 & 0.05 & 0.04 \\
\hline & third quartile & 0.56 & 0.10 & 0.08 \\
\hline & ninth decile & 0.80 & 0.15 & 0.12 \\
\hline & maximum & 1.22 & 0.26 & 0.20 \\
\hline \multirow{5}{*}{ 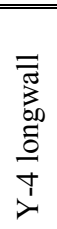 } & mean & 0.69 & 0.19 & 0.17 \\
\hline & median & 0.75 & 0.17 & 0.13 \\
\hline & third quartile & 0.98 & 0.27 & 0.23 \\
\hline & ninth decile & 1.19 & 0.33 & 0.31 \\
\hline & maximum & 1.48 & 0.74 & 0.59 \\
\hline \multirow{5}{*}{ 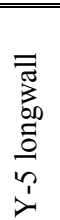 } & mean & 0.45 & 0.10 & 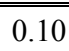 \\
\hline & median & 0.42 & 0.07 & 0.08 \\
\hline & third quartile & 0.73 & 0.11 & 0.13 \\
\hline & ninth decile & 0.88 & 0.20 & 0.25 \\
\hline & maximum & 1.05 & 0.50 & 0.40 \\
\hline
\end{tabular}

Both the effectiveness of mapping actual, i.e., measured conditions, and the limitations of individual models are similar [22,24]. Identification of these features and additional ex post tests allowed the development of the recommended procedure for conducting methane forecasts and scope selection of the methane prevention measures adequate to the level of risk (Fig. 6). The proposed algorithm incorporates the application, within the defined framework and scope, of all three selected methane prediction models from the longwall project preparation stage until the end of its lifecycle. 


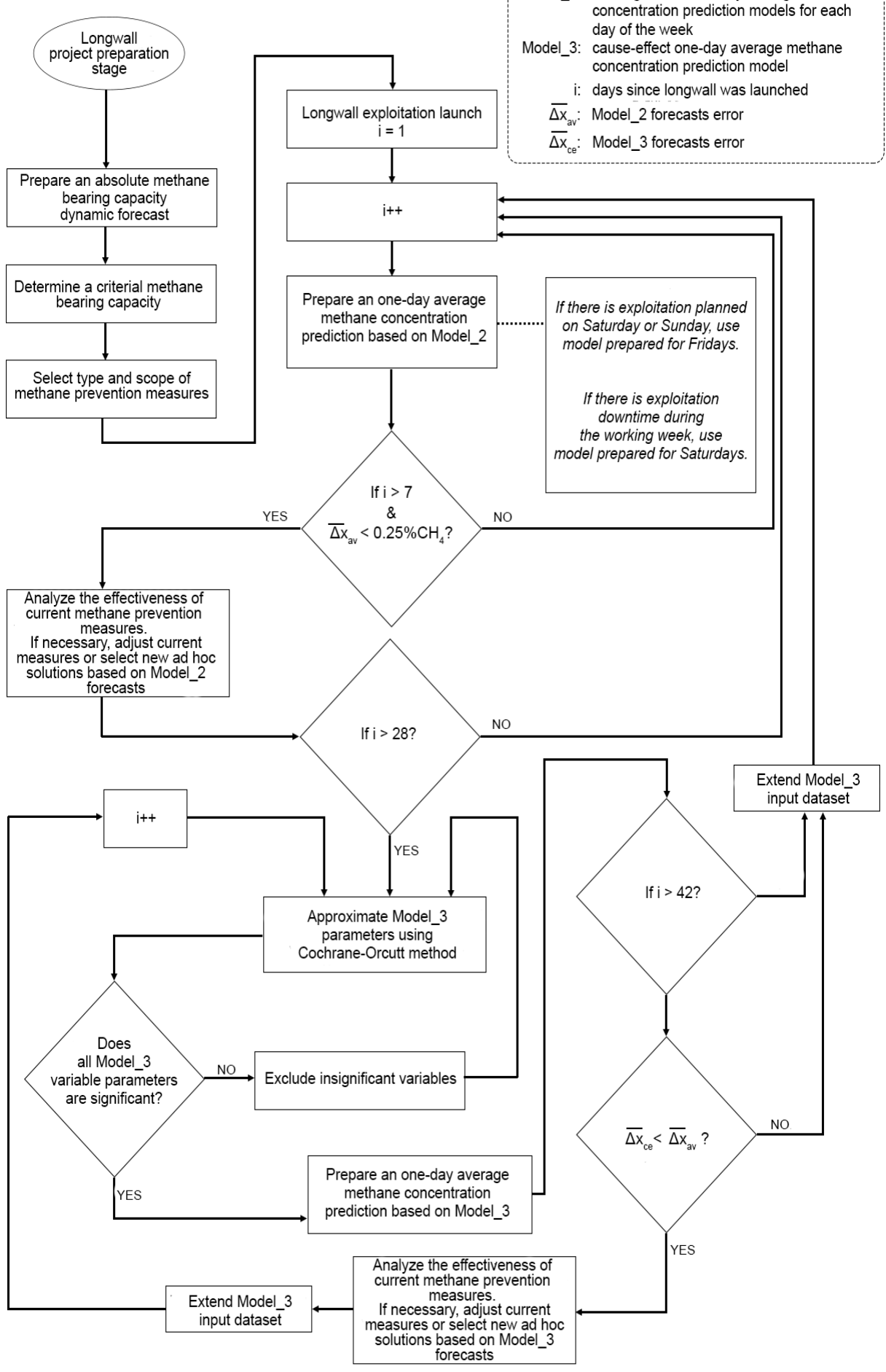

Fig. 6. The recommended procedure for conducting methane forecasts and scope selection of the methane prevention measures adequate to the level of risk [22]. 
At the longwall project preparation stage, it is recommended to prepare absolute methanebearing capacity dynamic predictions. These predictions should be the basis, among others, for the determination of criteria methane-bearing capacity and the pre-exploitation selection of means and the scopeof methane prevention measures, such as methane drainage efficiency. The next step, upon the second day of longwall operation, one-day average methane concentration predictions, based on a model with approximated parameters,should be made for each day of the week. The assumed in the algorithm initial 7-day lag is necessary to obtain a sample of the forecast data samplesto control the error value.

Thereafter, it is recommended to perform an analysis of the current prevention measures applied in the longwall area and to prepare a "catalogue" of selected ad hoc solutions dedicated to further methane prevention development. These solutions should be implemented immediately when the predicted methane concentration values suggest the possibility of exceeding the assumed safety threshold.

After a 28-day long initial period following the longwall launch, it is suggested to start preparing forecasts utilizing the cause-effect one-dayaverage methane concentration prediction model, which takes into account the impact of exploitation volume variables. Therefore, it is necessary to determine the model parameters based on the initial input dataset and to analyze the level of their significance. If one or more variables are excluded, due to the difficulty of reliable estimation of parameters, the model parameters should be approximated again. Similarly, as in the model_2 procedure steps, an additional 14-day delay period was assumed. It is recommended to use both short-term prediction models simultaneously during this period, while the model_2 results should be continuously used to adjust methane prevention measures.

After the estimated delay has elapsed, it is necessary to analyze and compare the errors of the forecasts prepared by model_2 and model_3. If the values of error parameters indicate that forecast preparing by model_2 should be maintained, it is recommended to also continue parallel forecasting according to the model_3 procedure and to control the distribution of both forecast errors. If the decision to discontinue implementing model_2 is made, model_3 forecasts should become the base for selecting and adjusting short-term methane prevention measures. It should be noted that all prediction models are errorburdened and should be used as a supportive tool. Any actions resulting in an adjustment of the prevention measure level should also be preceded by comprehensive analysis.

\section{Conclusions}

The research on the accuracy level of three prediction models presented in this article was conducted to develop the methodology of their application to select methane-prevention, especially impromptu, measures accurately. The identification of fluctuations in the occurring average daily methane concentrations in the longwall areas, even one day in advance, makes it easier to decide on the scope of adjustment measures. Besides, the trend analysis of the set of prepared forecasts, taking into account the model errors, allows us to plan less time-consuming preventive actions.

Appropriately prepared forecasts with acceptable error values should be treated as an aid to the decision-making processfor methane prevention.

The research implemented in seven selected longwall datasets provided for the identification of the strengths and weaknesses of particular prediction models. The advantage of absolute methane-bearing capacity dynamic prediction models (model_1) is the possibility of preparing forecasts that are dependent on the planned exploitation volume prior to the longwall launch. This model, based on the projected technical parameters of the designed longwall and geological surveys of the seam and the surrounding layers, provides for the determination of the basic parameters of the longwall ventilation and initial action 
plans aimed at reducing the methane hazard. However, the conducted research, preceding the longwall launch, that the absolute methane bearing capacity dynamic forecasts are characterized by a high error. It was also identified that the weakness of the dynamic model is the fact that it particularly poorly predicts the average daily methane concentrations at low exploitation volumes. Moreover, this model cannot be used when no production at the specific longwall is planned on a given day.

Autoregressive one-day average methane concentration prediction models for each day of the week (model_2) can be used practically from the second day after the longwall launch. The preparation of individual forecasts does not require time-consuming actions, as the parameters of these models prepared for each day of the week are known, and the only required variable is the average daily methane concentration registered on the day preceding the day under consideration. Determined forecast values are characterized by acceptable in the mining practiceerror values. During the course of the research, it was found that in some cases, connected usually to the weekly work rhythm disturbances, this model has a delayed reaction to changes in methane concentration. In the case of a sudden increase in registered daily methane concentration caused by atypical events, the forecast values are undervalued. The employee preparing the forecasts should be aware of the occurrence possibility of such prediction errors and follow with reports to identify these events.

The third forecast models selected in this study, i.e., a cause-effect one-day average methane concentration prediction model with the parameters approximated for the analyzed longwall (model_3), may be applied only after a particular period afterward the longwall launch. The author of this model indicates a 28-day minimum delay in its application intended for collecting the measurement input data. The analysis of the model indicates that this period is often sufficient to approximate the parameters of the model. However, there were also identified initial observation periods that required to extend the input measurement dataset. These exceptions indicate a requirement for individual parameter checking each time before the model is implemented. Analysis of the forecast errors parameters indicates that this model is characterized by higher accuracy of determining the average daily concentration of methane on the following day than the other models. Moreover, the advantage of this model is its capability to include exploitation volume on the preceding day and planned volume on the day for which the forecast is prepared as descriptive variables. This allows, similarly as in the case of the dynamic prediction model, to perform forecast sets of average daily methane concentrations depending on the particular quantities of exploitation. Such action allows the employee to find the value at which the high efficiency of the exploitation process is ensured and, at the same time, the acceptable level of methane hazard is not to be exceeded. Time-consumption is one of the model weaknesses. It is related to the necessity of daily model parameters approximation to obtain its maximum effectiveness. Each time in the process of determining the model parameters, it is necessary to identify and select variables that are statistically significant for the forecast daily average methane concentrations on the following day. This implies that the employee preparing the forecasts should have the knowledgeto critically analyze the parameters approximated by the Cochrane-Orcutt method.

The recommended procedure provides the capability of effective use of methane prediction to adjust the scope and means of preventive measures. The proper scope of methane prevention allows the mine to increase production efficiency by reducing the number of unplanned equipment downtime for the sake of maintaining mine safety and integrity. The costs resulting from the inadequacies of methane prevention measures that are appropriate for the methane hazard levels will be reduced [25]. Finally, prediction leads to an improvement in mine safety. 


\section{References}

1. S. Kędzior, M. Dreger, Methane occurrence, emissions and hazards in the Upper Silesian Coal Basin, Poland. International Journal of Coal Geology, 211, 103226. (2019).

2. L. Shi, J. Wang, G. Zhang, X. Cheng, X. Zhao, A risk assessment method to quantitatively investigate the methane explosion in underground coal mine, Process Safety and Environmental Protection, 107, 317-333 (2017).

3. V.B. Soloviov, R.D. Magomet, The ways of safety improvement during the outburstprone and gas bearing coal seams development, Journal of Industrial Pollution Control 33(1), 1042-1047. 2017.

4. J. Zawadzki, P. Fabijańczyk, H. Badura, A risk assessment method to quantitatively investigate the methane explosion in underground coal mine. International Journal of Coal Geology, 118, 33-44 (2013).

5. C.Ö. Karacan, W.P. Diamond, Forecasting gas emission for coal mine safety applications. In: Kissel F. (eD.): Handbook for Methane Control in Mining. Information Circular, vol.9486, National Institute for Occupational Safety and Health. Pittsburgh, PA., 113-126 (2006).

6. Regulation Rozporządzenie Ministra Energii z dnia 23 listopada 2016 r. w sprawie szczegółowych wymagań dotyczących prowadzenia ruchu podziemnych zakładach górniczych. DZ.U. z dnia 9 czerwca 2017 r. poz.1118. (2017)

7. E. Krause, K. Łukowicz Zasady prowadzenia ścian $w$ warunkach zagrożenia metanowego. Technical Guide. (GIG, KD Barbara Publishing House. Katowice Mikołów, 2004).

8. H. Badura, Analysis of some factors influence on methanebearing capacity of longwall D-2 region in seam 409/4 in colliery "R". Przegląd Górniczy, 4 (2007).

9. J. Krawczyk, J. Janus, The Numerical Simulation of a Sudden Inflow of Methane into the End Segment of a Longwall with Y-Type Ventilation System. Archives of Mining Sciences, 59(4), 941-957 (2014).

10. E. Krause, J. Skiba Formation of methane hazard in longwall coal mines with increasingly higher production capacity. International Journal of Mining Science and Technology, 24(3), 403-407 (2014).

11. R. Krog, S. Schatzel, F. Garcia, J. Marshall, Predicting methane emissions from longer longwall faces by analysis of emission contributors. Proceedings of the 11th U.S./North American Mine Ventilation (2006).

12. S.A. Nikolaevich, T.S. Vadimovich, G.E. Vladimirovich, Complex technology of underground coal gasification and coal-based methane recovery using geodynamic zoning. 18th International Coal Preparation (2016).

13. J. Sułkowski, Wspieranie przez naukę zwalczania pożarów i wybuchów w kopalniach węgla kamiennego. Silesian University of Technology Publishing House. Górnictwoi Geologia, Gliwice, 5, 3 (2010).

14. N. Szlązak, M. Borowski, L. Kloc, D. Obracaj, Inequality of air heating in downcast shaft and its effect on the disturbance of flow directions, Górnictwo, AGH Publishing House, Kraków 24, 4 (2000).

15. S. Trenczek, Study of influence of tremors on combined hazards. Longwall mining operations in cooccurrence of natural hazards. A case study. Journal of Sustainable Mining, 15(1), 36-47 (2016). 
16. H. Badura, Short-term prediction methods for methane concentrations at the outlets from caving longwall areas at coal mines. Monograph. (Silesian University of Technology Press, Gliwice, 2013).

17. C.Ö. Karacan Modeling and prediction of ventilation methane emission of U.S. long wall mines using supervised artificial neural networks. International Journal of Coal Geology, 73(3-4), 371-387 (2008).

18. C.Ö. Karacan Forecasting gob gas venthole production using intelligent computing methods for optimum methane control in longwall coal mines. International Journal of Coal Geology, 79(4), 131-144 (2009).

19. L.W. Lunarzewski, Gas emission prediction and recovery in underground coal mines. International Journal of Coal Geology, 35(1-4), 117-145 (1998).

20. D. Mishra, D. Panigrahi, P. Kumar, Computational investigation on effects of geomining parameters on layering and dispersion of methane in underground coal mines a case study of Moonidih Colliery, Journal of Natural Gas Science and Engineering, 53, 110-124 (2018).

21. K. Noack, Control of gas emissions in underground coal mines. International Journal of Coal Geology, 35 (1-4), 57-82 (1998).

22. A.P. Niewiadomski, Short-term prediction method selection criteria in order of proper selection of methane prevention measures in longwalls. (PhD dissertation, 2019).

23. E. Krause, K. Łukowicz, Dynamiczna prognoza metanowości bezwzględnej ścian. Technical Guide (GIG, KD Barbara Publishing House. Katowice - Mikołów, 2000).

24. A.P. Niewiadomski, H. Badura, Evaluation of a one-day average methane concentrations forecast at the outlet from the longwall ventilation region as tool of supporting selection of methane prevention measures, Topical Issues of Rational Use of Natural Resources 2019, Volume 1: Proceedings of the XV International ForumContest of Students and Young Researchers under the auspices of UNESCO, (2019)

25. J. Dong, Y. Cheng, T. Chang, J. Zhang, S. Guo, Coal mine methane control cost and full cost: The case of the Luling Coal Mine, Huaibei coalfield, China. Journal of Natural Gas Science and Engineering, 26, 290-302 (2015). 